\title{
Inhibition of HIV-1 Replication by Secondary Metabolites From Endophytic Fungi of Desert Plants
}

\author{
Brian P. Wellensiek ${ }^{1,+}$, Rajesh Ramakrishnan ${ }^{1,++}$, Bharat P. Bashyal ${ }^{2}$, Yvette Eason ${ }^{1}$, \\ A. A. Leslie Gunatilaka ${ }^{2}$ and Nafees Ahmad ${ }^{*}, 1$ \\ ${ }^{I}$ Department of Immunobiology, College of Medicine and ${ }^{2}$ Southwest Center for Natural Products Research and \\ Commercialization, College of Agriculture and Life Sciences, University of Arizona, Tucson, AZ 85724, USA
}

\begin{abstract}
Most antiretroviral drugs currently in use to treat an HIV-1 infection are chemically synthesized and lead to the development of viral resistance, as well as cause severe toxicities. However, a largely unexplored source for HIV-1 drug discovery is endophytic fungi that live in a symbiotic relationship with plants. These fungi produce biologically active secondary metabolites, which are natural products that are beneficial to the host. We prepared several hundred extracts from endophytic fungi of desert plants and evaluated the inhibitory effects on HIV-1 replication of those extracts that showed less than $30 \%$ cytotoxicity in T-lymphocytes. Those extracts that inhibited viral replication were fractionated in order to isolate the compounds responsible for activity. Multiple rounds of fractionation and antiviral evaluation lead to the identification of four compounds, which almost completely impede HIV-1 replication. These studies demonstrate that metabolites from endophytic fungi of desert plants can serve as a viable source for identifying potent inhibitors of HIV-1 replication.
\end{abstract}

Keywords: Drug discovery, endophytic fungi, HIV-1, secondary metabolites.

\section{INTRODUCTION}

Several strides have been made in understanding the molecular mechanisms of pathogenesis of human immunodeficiency virus type 1 (HIV-1) infection since the discovery of the virus in 1983 [1,2]. This understanding has highlighted several critical points in the HIV-1 lifecycle that can be targeted for development of anti-retroviral drugs [3]. Along these lines, many anti-retroviral drugs have been developed to target the viral enzymes reverse transcriptase, integrase and protease, as well as the viral proteins which facilitate entry into the host cell [4]. When used in a clinical setting, these drugs have been shown to greatly reduce viral load and significantly improve patient survival. However, due to the relatively high mutation rate associated with HIV-1 replication, continued exposure of the virus to a specific antiviral leads to the development of drug-resistant viral strains. This, in turn, creates a need to treat patients with an ever-changing regimen of drugs, all of which have several toxic side effects [5]. These factors create treatment options which are not ideal, and can lead to barriers that hinder effective management of the infection. The development of new antiviral drugs that are able to sufficiently inhibit HIV-1 replication with little adverse side effects is tantamount if there is to be any progress towards stopping the HIV-1 epidemic.

\footnotetext{
*Address correspondence to this author at the Department of Immunobiology, College of Medicine, University of Arizona, Tucson, AZ 85724, USA; TeL: 520-626-7022; Fax: 520-626-2100;

E-mail:nafees@u.arizona.edu
}

${ }^{+}$Present address: The Biodesign Institute at Arizona State University, Tempe, AZ, USA; ${ }^{++}$Department of Obstetrics and Gynecology, Baylor College of Medicine, Houston, TX, USA
Most anti-retroviral drugs used today are chemically synthesized in laboratories. While this approach has resulted in drugs that can inhibit HIV-1 and be produced relatively easily, these drugs have not been able to provide a way to completely prevent or terminate an HIV-1 infection in patients as well as avoid side effects and development of resistance. Optimization of these existing drugs is clearly important work but may never fully alleviate the problems in using them for treatment. However, exploring new avenues of drug discovery could lead to the development of more ideal treatment or prevention options. A relatively untapped resource for anti-HIV-1 drug discovery lies in natural products found in plants and their associated fungi [6]. These products of natural origin have been studied in the context of other diseases, such as cancer, and several chemotherapeutic drugs have resulted from these studies [7, 8]. In fact, approximately $60 \%$ of the anticancer and anti-infective agents which are commercially available are of natural origin [9].

A source of several natural products has been the endophytic fungi that live within desert plants [10]. These fungi reside within the stems, roots and leaves of plants in a symbiotic relationship. The plant protects and feeds the fungi, which in turn produces bioactive (plant growth regulatory, antibacterial, antifungal, antiviral, insecticidal, antidrought, anticold, antiheat) substances to enhance the growth and competitiveness of the plant and to protect it from herbivores and plant pathogens [11]. These bioactive substances have been isolated and characterized, leading to the development of drugs such as Taxol (anticancer) [12], Cryptocandin (antimycotic) [13], Preussomerin D (antimicrobial) [14] and Sequoiatone A and B (antitumor) [15]. Some studies have identified substances that inhibit 
viruses [16, 17], specifically the cytonic acids A and B isolated from endophytic fungi were found to inhibit the human cytomegalovirus protease enzyme [18]. However, the effect of compounds from endophytic fungi on anti-viral activity, especially anti-HIV, has been largely unexplored $[19,20]$. It is apparent that the potential for the discovery of compounds having antiviral activity from endophytic fungi is in its infancy. To this end, we have employed tissue culture assays to evaluate the inhibitory properties of crude extracts, fractions, and compounds from the endophytic fungi of desert plants on an HIV-1 infection. We evaluated several hundred extracts from endophytic fungi and identified a number of compounds from these extracts that completely (100\%) inhibit HIV-1 replication in Tlymphocytes. These results show promise towards developing new non-toxic and potent anti-HIV drugs from endophytic fungi.

\section{RESULTS}

\section{Evaluation of Antiviral Capabilities of Endophytic Fungal Extracts}

We first determined the cytotoxicity of the endophytic fungal extracts in T-lymphocytes. Each of the fungal extracts was evaluated for cytotoxicity by incubating (a T4lymphocyte cell line) with various concentrations of the extracts over a period of nine days. The toxic effects to the A3.01 cells were determined every three days using the MTT assay. Varying cytoxicity levels were seen when evaluating the individual fungal extracts. When observed, the highest levels of toxicity occurred on day nine of culture, and all cytotoxicity values given refer to toxicity observed on this day. Several hundred extracts were evaluated, however only extracts that displayed $30 \%$ toxicity or less were chosen for further studies, and 100 extracts were found to meet this requirement. Initial experiments revealed that extracts CS, CT, B, G, and I displayed low levels of toxicity towards A3.01 cells at a concentration of $2 \mu \mathrm{g} / \mathrm{mL}$, resulting in $25 \%$, $19 \%, 10 \%, 15 \%$ and $22 \%$ cell death respectively, when compared to non-treated cells (data not shown).

Based on the toxicity results the effects of these extracts on HIV-1 replication was determined by infecting A3.01 cells with $\mathrm{HIV}-1_{\mathrm{LAV}}$ in the presence of the extracts at a 2 $\mu \mathrm{g} / \mathrm{mL}$ concentration. The inhibition levels of the extracts tested were determined by comparison with the DMSO (solvent) control at peak days of virus production. Azidothymidine (AZT), a known reverse transcriptase inhibitor [23], was used as positive control. The level of viral replication present in each culture was measured using the reverse transcriptase (RT) assay every three days until viral replication began to naturally decrease. Each of these extracts inhibited HIV-1 replication to varying degrees. Approximately half (52) of the extracts tested resulted in inhibition between 0 and 25\%, another 25 showed $25-50 \%$ inhibition, 19 inhibited viral replication from 50 to $75 \%$, and only 4 displayed inhibition between 75 and 99\%. A representative graph is shown in Fig. (1). Extracts CS and CT each resulted in around 25\% inhibition of HIV-1 replication. Extract I inhibited replication by $38 \%$, and interestingly, extracts $B$ and $G$ inhibited viral replication almost completely (96 and 99\%). In the case of extracts B and $\mathrm{G}$, the levels of virus present in culture supernatants were just above that of the uninfected (mock) control. Based on these results, extracts B, G and I were chosen for further investigation.

\section{Evaluation of Large Scale Endophytic Fungal Extracts and Fractions}

In order to evaluate the individual compounds within the fungal extracts that were responsible for conveying antiviral capabilities, extracts B, G and I were fractionated. A diagram detailing the full fractionation of these extracts is shown in Fig. (2). The fungal cultures were grown on a large scale to obtain sufficient extracts for fractionation. These large-scale extracts and fractions were then evaluated for cytotoxicity using the MTT assay as before at concentrations of 2, 4, 8, and $16 \mu \mathrm{g} / \mathrm{mL}$. This spread of concentrations was used, as it was believed that the toxic concentrations of the individual fractions would vary from the unfractionated extracts. As can be seen in Fig. (3a), the toxicity of the large scale extracts and fractions increased in a dose dependent manner. Toxicity of each large-scale extract and fraction was determined as percent of cellular survival compared to the solvent control, which contained the concentration of DMSO

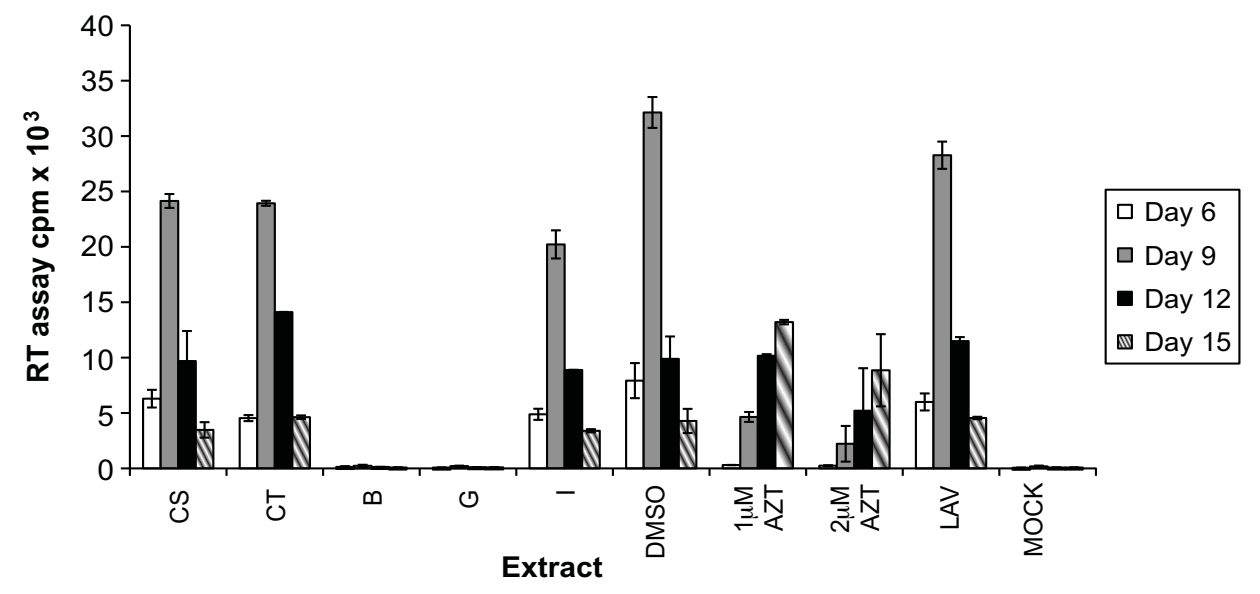

Fig. (1). Effect of endophytic fungal extracts on HIV-1 replication. This graph is representative of results seen in all 100 extracts tested. A3.01 cells were infected with HIV-1 $1_{\text {LAV }}$ in the presence of the extracts CS, CT, B, G and I at a concentration of $2 \mu \mathrm{g} / \mathrm{mL}$. Controls for DMSO concentration present in extract wells (DMSO), positive inhibition of viral replication ( $1 \mu \mathrm{M}$ and $2 \mu \mathrm{M}$ AZT), and absence of extract (LAV) and virus (mock) were included. Virus levels in culture supernatant were determined by RT assay. 


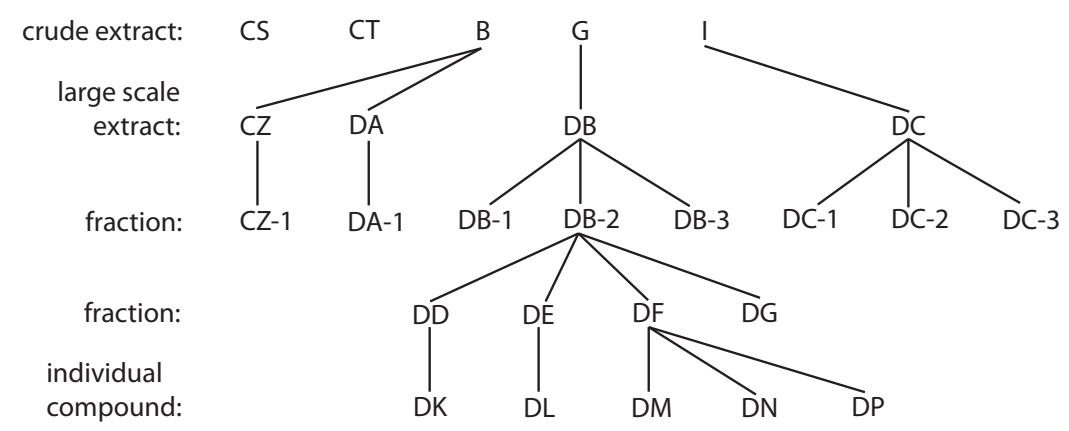

Fig. (2). Flowchart of fractionation leading to isolation of individual compounds. Several extracts, which displayed antiviral activity, underwent numerous rounds of fractionation, the culmination of which lead to the isolation of individual compounds.

that was present in each large-scale extract/fraction culture. Each large-scale extract and fraction was not toxic at 2 or 4 $\mu \mathrm{g} / \mathrm{mL}$, except for DB-2, which showed $44 \%$ toxicity. At 8 $\mu \mathrm{g} / \mathrm{mL}$, all of the tested extracts were not toxic except the large-scale extract DB (83\% toxicity) and its fraction DB-2 ( $89 \%$ toxicity). When the concentration was increased to 16 $\mu \mathrm{g} / \mathrm{mL}$ toxicity levels varied from $85 \%$ with DB-2 to $8 \%$ with DC-3. The observed toxicities were not due to the presence of DMSO in the cultures as no toxicity was seen in the solvent control (Fig. 3a).
Based on these cytotoxicity results, concentrations for the evaluation of these large scale extracts and fractions on $\mathrm{HV}$ 1 replication were chosen. All samples, except for DB and DB-2, were tested at a concentration of $8 \mu \mathrm{g} / \mathrm{mL}$. Largescale extract DB was evaluated at a concentration of 2 $\mu \mathrm{g} / \mathrm{mL}$, while DB-2 was tested at concentrations of $0.25,0.5$ and $1 \mu \mathrm{g} / \mathrm{mL}$. Inhibition of viral replication was carried out as before by the infection of A3.01 cells in the presence of the large-scale extract or its fraction. All samples, except fraction DB-3, showed the ability to inhibit HIV-1

a

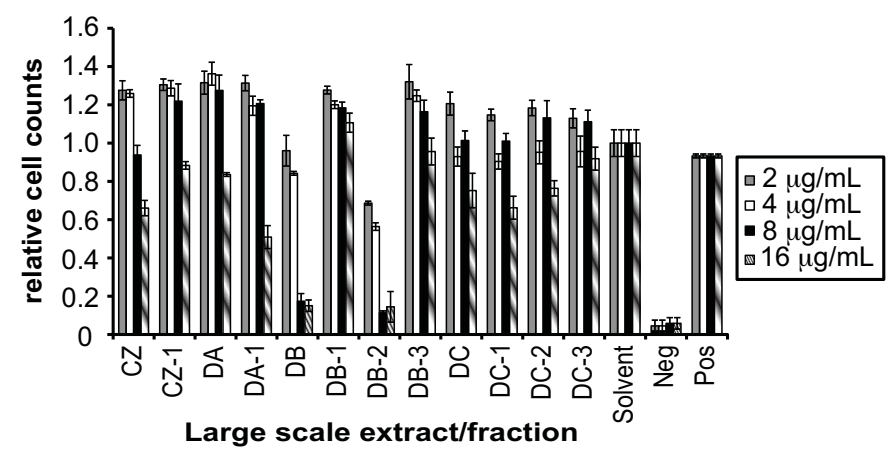

b

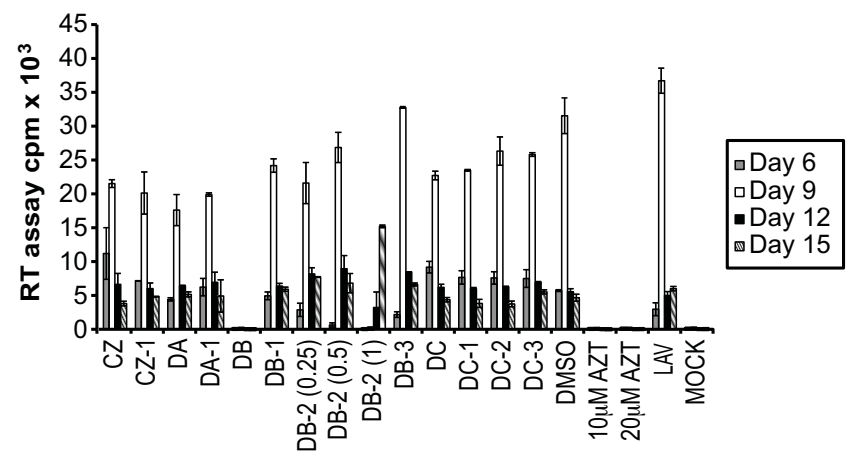

Large scale extract/fraction

Fig. (3). Evaluation of large-scale extracts and fractions. (a) Each large scale extract and the fractions that originated from it were evaluated for cytotoxicity using the MTT assay. Controls for DMSO concentration (solvent), complete cell death (negative) and no treatment (positive) were also performed. The \% cellular survival was determined by comparison with the solvent control. (b) Inhibition of large-scale extracts and fractions was determined by infecting A3.01 cells with HIV-1 $1_{\text {LAV }}$ in the presence of the large scale extracts and fractions at 8 $\mu \mathrm{g} / \mathrm{mL}$ (except for DB, $2 \mu \mathrm{g} / \mathrm{mL}$, and DB-2, 0.25, 0.5, $1 \mu \mathrm{g} / \mathrm{mL}$ ). Controls for DMSO concentration present in extract wells (DMSO), positive inhibition of viral replication $(10 \mu \mathrm{M}$ and $20 \mu \mathrm{M} \mathrm{AZT})$, and absence of extract (LAV) and virus (mock) were included. Virus levels in culture supernatant were determined by RT assay. 
replication to some degree (Fig. 3b). Inhibition ranged from $17 \%$ with DC-2, to almost $100 \%$ inhibition with the large scale extract DB. This inhibition was comparable to the levels of inhibition by the reverse transcriptase inhibitor AZT. The inhibitory capabilities of DB appear to be derived from the fraction DB-2, which inhibited viral replication almost completely at the day of peak virus production in the solvent control, and delayed the peak of virus production by 6 days (Fig. 3b).

\section{Evaluation of DB-2 Fractions}

The fraction DB-2 displayed the largest amount of HIV-1 replication inhibition (Fig. 3b). As this fraction arose from only one round of fractionation of the large-scale extract DB, it was possible that more than one compound was present within DB2. Therefore, DB-2 was subjected to a second round of fractionation to give rise to the fractions DD, DE, DF and DG. As DB-2 was toxic at lower concentrations in previous experiments (Fig. 3a), MTT assays were performed with DD, DE, DF and DG at lower concentrations of 0.1, 0.2, 0.5, 1 and 2 $\mu \mathrm{g} / \mathrm{mL}$ (Fig. 4a). Fractions DD, DF, and DG displayed toxic effects only at the highest concentration tested $(2 \mu \mathrm{g} / \mathrm{mL})$. Fraction DE was toxic at $1 \mu \mathrm{g} / \mathrm{mL}$ ( $70 \%$ toxicity), however was not toxic at $0.5 \mu \mathrm{g} / \mathrm{mL}$. All the fractions were at least $70 \%$ toxic at a concentration of $2 \mu \mathrm{g} / \mathrm{mL}$.

Using the above described cytotoxicity results as a guide, fractions DD, DE, DF and DG were evaluated for their ability to inhibit HIV-1 replication. DD, DF and DG were all tested at a concentration of $1 \mu \mathrm{g} / \mathrm{mL}$, while $\mathrm{DE}$ was evaluated at $0.5 \mu \mathrm{g} / \mathrm{mL}$. All of the fractions inhibited HIV-1 replication, with the lowest amount of inhibition occurring with DG at $35 \%$ (Fig. 4b). Fraction DF inhibited replication by $60 \%$, while DD and DE displayed almost $100 \%$ inhibition at the day of peak virus production. This inhibition was greater than that of the known reverse transcriptase inhibitor AZT.

\section{Evaluation of Pure Isolated Compounds}

To isolate the individual compounds from DD, DE and DF, which all inhibited HIV-1 replication (Fig. 4b), the fractions underwent one final round of fractionation. The compounds displayed varying levels of toxicity when compared to the solvent control (Fig. 5a). Compound DK was not toxic at a concentration of $1.5 \mu \mathrm{g} / \mathrm{mL}$, while compound DL reached acceptable toxicity levels at 0.5 $\mu \mathrm{g} / \mathrm{mL}$. Compounds DM, DN and DP were mildly toxic, with the greatest toxicity $(31 \%)$ occurring at $1 \mu \mathrm{g} / \mathrm{mL}$ with DP. All compounds tested were almost completely toxic at 2 $\mu \mathrm{g} / \mathrm{mL}$, with the exception of $\mathrm{DN}$, which was $46 \%$ toxic at that concentration.

Based on the cytotoxicity results, the individual compounds were evaluated for their ability to inhibit HIV-1 replication in A3.01 cells. Compounds DK, DM, DN and DP were tested at a concentration of $1.5 \mu \mathrm{g} / \mathrm{mL}$, while DL was
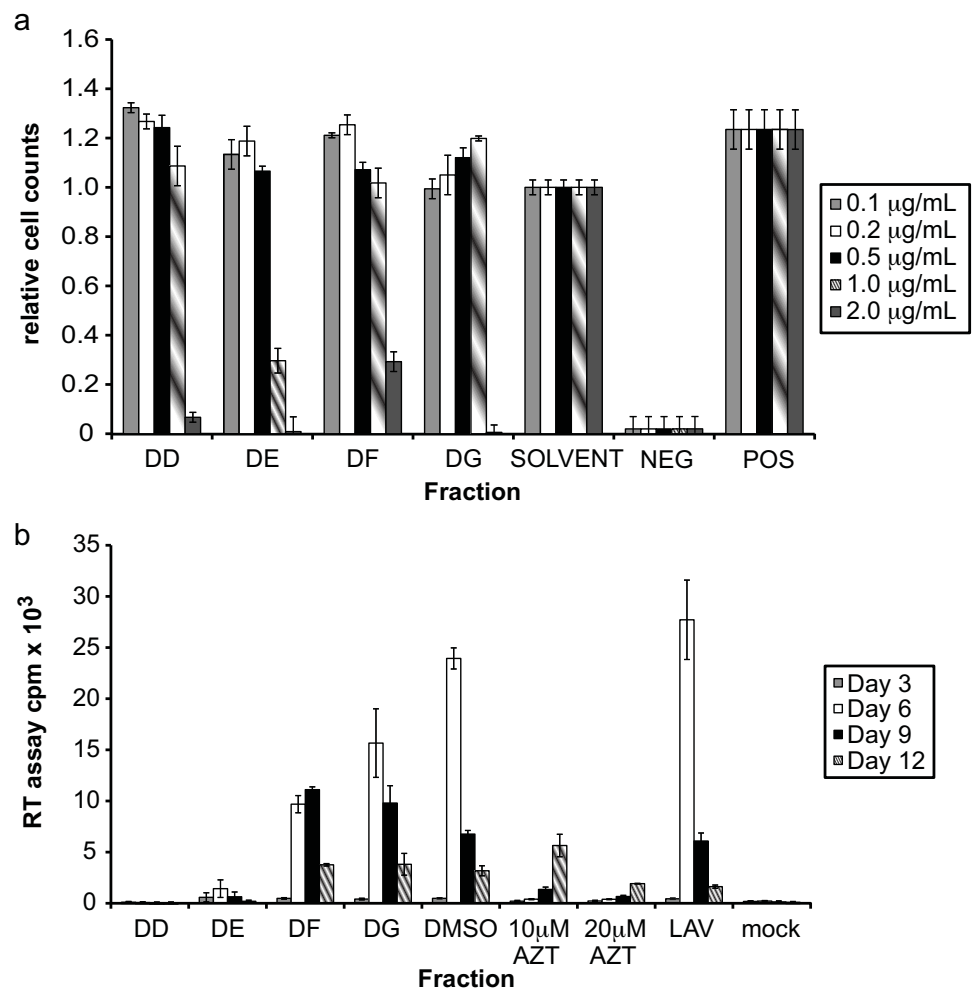

Fig. (4). Effects of DB-2 fractions. (a) Each fraction was evaluated for cytotoxicity using the MTT assay. Controls for DMSO concentration (solvent), as well as positive (cells alone) and negative (addition of 100\% DMSO) controls were performed. The \% of cellular survival was determined in each culture containing a fraction by comparison with the solvent control. (b) A3.01 cells were infected with HIV-1 $1_{\text {LAV }}$ in the presence of the DB-2 fractions DD, DE, DF and DG to determine the effect on viral replication. DD, DF and DG were tested at $1 \mu \mathrm{g} / \mathrm{mL}$, while DE was tested at $0.5 \mu \mathrm{g} / \mathrm{mL}$. Controls for DMSO concentration present in extract wells (DMSO), positive inhibition of viral replication (10 $\mu \mathrm{M}$ and $20 \mu \mathrm{M} \mathrm{AZT)}$, and absence of extract (LAV) and virus (mock) were included. Virus levels in culture supernatant were determined by RT assay. 

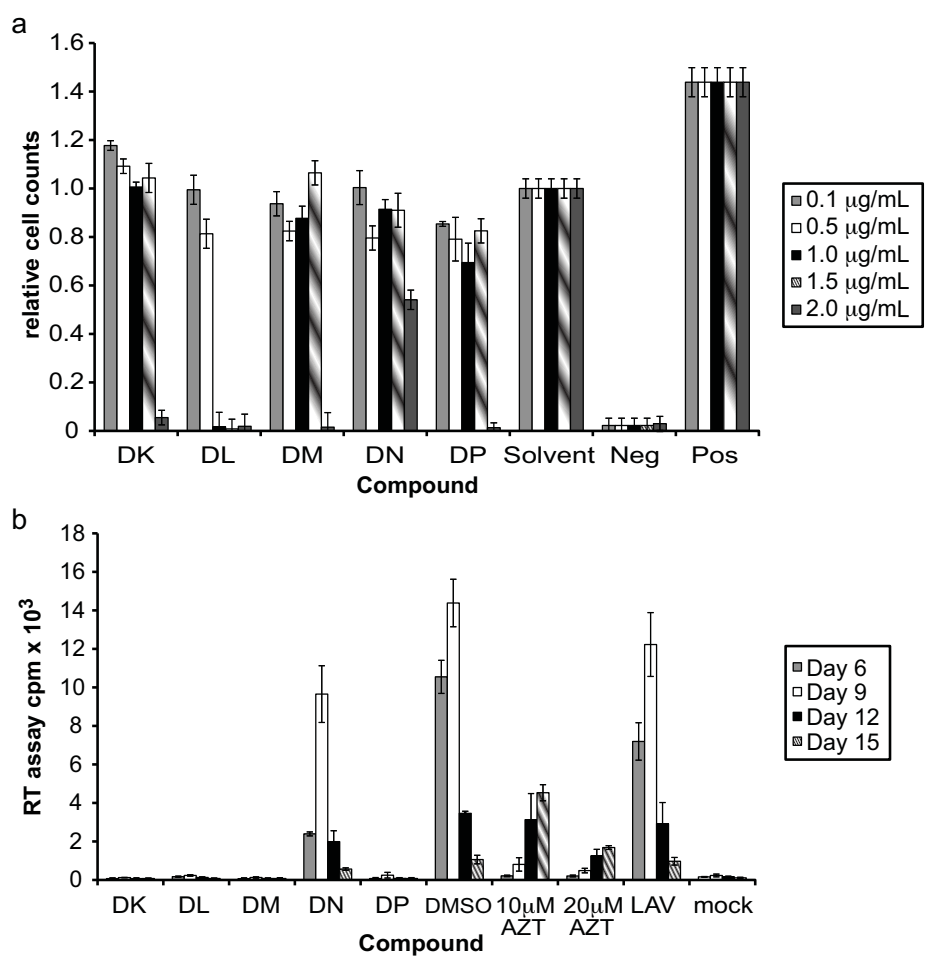

Fig. (5). Efficacy of isolated individual compounds. (a) MTT assays were performed to determine the cytotoxicity of the compounds against A3.01 cells. Controls for DMSO concentration (solvent), as well as positive (cells alone) and negative (addition of 100\% DMSO) controls were performed. The $\%$ of cellular survival was determined by comparison with the solvent control. (b) The effect of the individual compounds DK, DL, DM, DN and DP on HIV-1 replication was determined by infecting A3.01 cells with HIV-1 $1_{\text {LAV }}$ in the presence of the compounds. DK, DM, DN and DP were tested at $1.5 \mu \mathrm{g} / \mathrm{mL}$, while DL was tested at $0.5 \mu \mathrm{g} / \mathrm{mL}$. Controls for DMSO concentration present in extract wells (DMSO), positive inhibition of viral replication (10 $\mathrm{MM}$ and $20 \mu \mathrm{M}$ AZT), and absence of extract (LAV) and virus (mock) were included. Virus levels in culture supernatant were determined by RT assay.

evaluated at $0.5 \mu \mathrm{g} / \mathrm{mL}$. Compound $\mathrm{DN}$ inhibited viral replication by $33 \%$ at the peak day of viral production, while DK, DL, DM and DP inhibited viral replication almost completely (97-99\%) (Fig. 5b). This inhibition was greater than that of the highest concentration of AZT, $97 \%$ at $20 \mu \mathrm{M}$. In addition, RT counts were barely over that of the mock infected (no virus added to the culture) control.

\section{Titration of Anti-HIV-1 Activity}

At the highest non-cytotoxic dose possible, compounds DK, DL, DM and DP inhibit HIV-1 replication almost completely (Fig. 5a, b). To determine the minimum dose required for significant antiviral activity, each compound was screened at decreasing concentration intervals until viral replication increased (Fig. 6a-d). For all assays, antiviral activity was evaluated nine days post-infection, the day of peak viral replication in the untreated infection control. Low levels of viral replication began to appear at a concentration of $0.3 \mu \mathrm{g} / \mathrm{mL}$ for compound $\mathrm{DK}$, which had a calculated $50 \%$ inhibitory concentration $\left(\mathrm{IC}_{50}\right)$ of $0.1 \mu \mathrm{g} / \mathrm{mL}$ (Fig. 6a). Compounds DL and DM were more effective at lower concentrations, with noticeable viral replication at 0.1 and $0.075 \mu \mathrm{g} / \mathrm{mL}$, and $\mathrm{IC}_{50}$ 's of 0.075 and $0.03 \mu \mathrm{g} / \mathrm{mL}$, respectively (Fig. 6b, c). Much higher concentrations were required for compound DP to be effective, with viral replication returning at a concentration of $0.75 \mu \mathrm{g} / \mathrm{mL}$ and an $\mathrm{IC}_{50}$ of $0.5 \mu \mathrm{g} / \mathrm{mL}$ (Fig. 6d). Combining the titration and cytotoxicity data for DK, DL, DM and DP, the therapeutic indexes for these compounds was determined to be $15,6.5$, 50 , and 3 , respectively.

\section{Determination of Reverse Transcriptase Inhibition by Pure Endophytic Fungal Compounds}

The compounds DK, DL, DM and DP all inhibited HIV1 replication nearly $100 \%$ (Fig. 5b). As viral replication was measured by RT assay of the culture supernatant, the effect of these compounds on reverse transcriptase enzyme activity was determined to rule out false positives for viral replication inhibition. Aliquots of the same virus were used for each assay performed to assure that the same amount of virus was present, and each compound was evaluated at a concentration of $1.5 \mu \mathrm{g} / \mathrm{mL}$. Upon determination of the levels of radioactive incorporation by RT enzyme activity, the compounds displayed little ability to inhibit RT function (Table 1). The maximum amount of inhibition seen was $6 \%$ with DM, however this $6 \%$ inhibition was also seen in the solvent (DMSO) control.

\section{DISCUSSION}

In this study, we have evaluated the effects of several hundred endophytic fungal extracts on HIV-1 replication in T-lymphocytes, the major target cell for HIV-1, and provide evidence that metabolites produced by these endophtic fungi possesses anti-retroviral activities. We have identified four non-toxic extracts that exhibited inhibitory effects on HIV-1 replication in the range of $75 \%$ to $99 \%$ in T-lymphocytes. In 
a

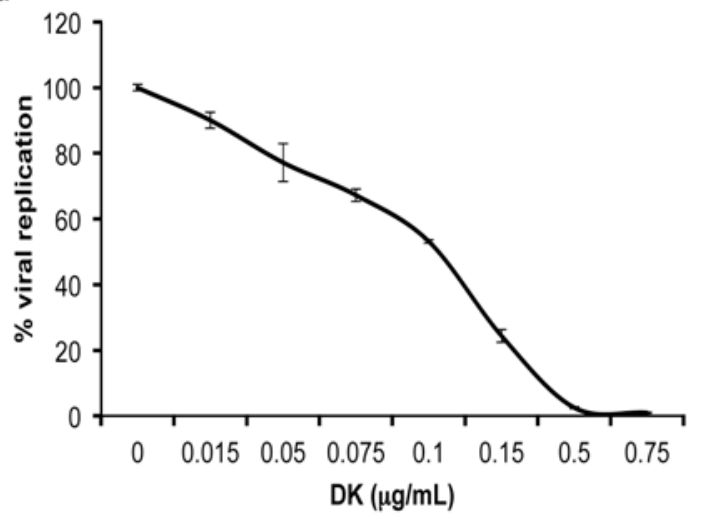

C

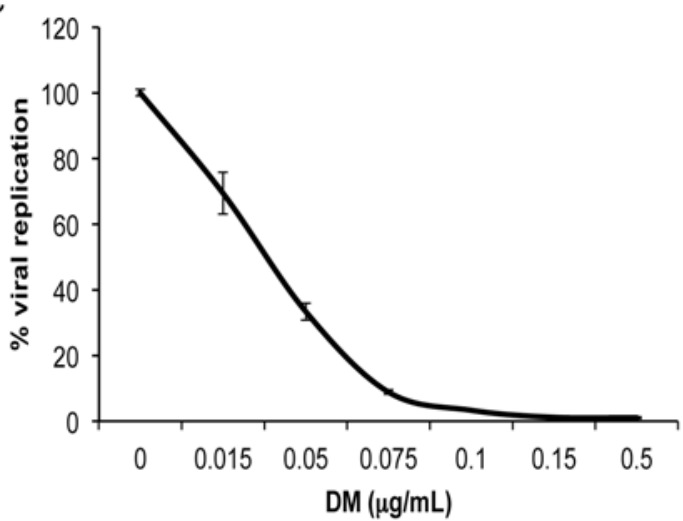

b

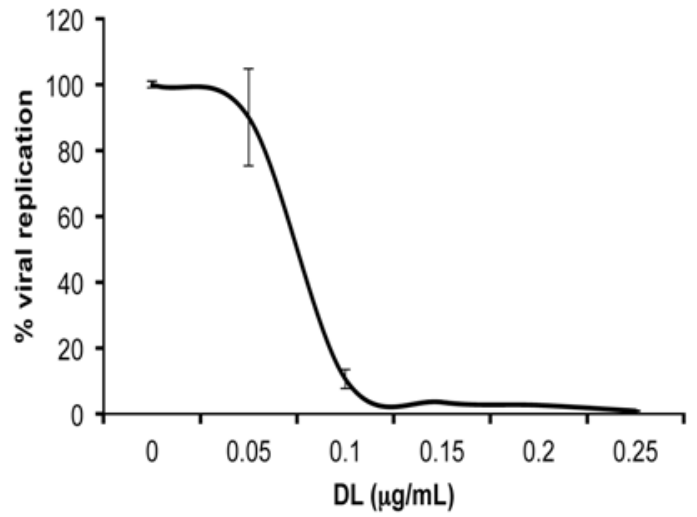

d

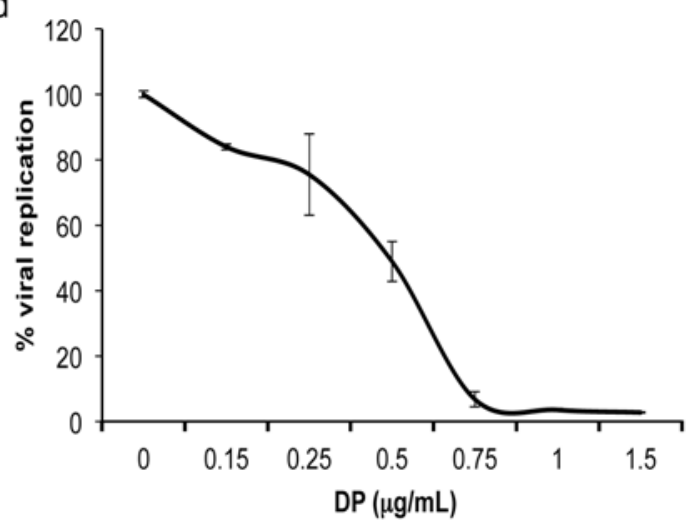

Fig. (6). HIV-1 replication dose response to individual compounds. The range of concentrations at which compounds DK (a), DL (b), DM (c) and DP (d) effectively inhibit HIV-1 replication was determined by infecting A3.01 cells with HIV-1 $1_{\text {LAV }}$ in the presence of decreasing amounts of the compounds. Virus levels in culture supernatant were determined by RT assay, and \% of viral replication was determined by comparison with the untreated (concentration of 0 ) control.

addition, three of these extracts were fractionated and fraction DB-2 completely inhibited HIV-1 replication at a concentration that was not cytotoxic. Moreover, further fractions of DB-2, including DD and DE, and DF inhibited HIV-1 replication by $100 \%$ and $60 \%$, respectively. Furthermore, purified compounds DK, DL, DM and DP completely inhibited HIV-1 replication at concentrations of $0.5-1.5 \mu \mathrm{g} / \mathrm{mL}$, which was comparable to the widely used antiretroviral drug AZT (azidothymidine) at a $20 \mu \mathrm{M}$ concentration [23]. This information demonstrates that metabolites from endophytic fungi can be potent inhibitors of HIV-1 replication and should be explored for new and non-toxic anti-HIV drug development.

The endophytic fungal species that the potent HIV-1 inhibitors were isolated from was Alternaria tenuissima, which inhabits the stem of the Sonoran desert plant Quercus emoryi. Early structure determination of these potent inhibitors revealed that the active compounds belong to a class of natural pigments known as perylenequinones. This class of pigments has previously been reported to have antiviral activity against herpes simplex virus type 1 and Sindbis virus [24] as well as protein kinase C inhibitory activity [25]. A more elaborate structural analysis of these compounds is underway to determine specific protein domains involved in antiviral activity, and the details of this study will be presented in a separate communication.
Table 1. Effect of Endophytic Compounds on HIV-1 Reverse Transcriptase

\begin{tabular}{|c|c|}
\hline Compound & \% RT Activity \\
\hline \hline DK & $95+/-2$ \\
\hline DL & $100+/-10$ \\
\hline DM & $94+/-3$ \\
\hline DP & $100+/-1$ \\
\hline DMSO & $94+/-5$ \\
\hline LAV & $100+/-0$ \\
\hline Mock & $0+/-0$ \\
\hline
\end{tabular}

Inhibition of reverse transcriptase (RT) enzyme activity was determined by performing RT assays in the presence of the compounds DK, DM and DP at a concentration of 1.5 $\mu \mathrm{g} / \mathrm{mL}$, and DL at a concentration of $0.5 \mu \mathrm{g} / \mathrm{mL}$. Controls for DMSO concentration present in compound wells (DMSO) and absence of compound (LAV) were included. A control with no virus present (mock) was also performed.

Using endophytic fungal extracts for drug discovery has been extensively studied in other areas, such as cancer research [9], however the anti-HIV-1 potential of these extracts has been largely unexplored [10]. To obtain the fungal extracts, several hundred endophytic fungi were isolated from various desert plants, and crude extracts were made by lysis of the fungi. As many of these fungi produce 
bioactive substances [11], the toxicity was determined. It was important to determine the cytotoxicity of the extracts because the goal of an anti-HIV-1 drug screen is to maintain cell viability while eliminating or inhibiting the virus. A large number of extracts proved to be toxic, however 100 of them showed low enough toxicity levels $(<30 \%)$ to continue with further studies (Fig. 3a). The antiviral capability of these extracts was determined by assessing their effects on viral replication in an infected A3.01 cell culture. While many extracts did not display any negative effects on viral replication, a few promising ones were discovered (Fig. 1). The fact that these crude extracts were able to inhibit HIV-1 replication suggested that one or more compounds within the extracts were affecting the viral lifecycle at some point. To this end, the promising extracts were fractionated in order to isolate these individual compounds. Several rounds of fractionation were carried out and the fractions were evaluated for toxicity and antiviral effects after every round. The fractions that were non-toxic and inhibited HIV-1 replication were further fractionated until single compounds were isolated. The end result of the fractionations was the isolation of four compounds from endophytic fungal extracts that almost completely inhibited viral replication (Fig. 5b). This level of inhibition is comparable to that seen with the use of the antiretroviral drug AZT, which has been used for decades to treat an HIV-1 infection. While the calculated therapeutic indexes for the compounds isolated in this study are low, it does provide a narrow window to further explore the use of these compounds as a possible method of treatment. These studies demonstrate that not only can endophytic fungi be a useful source for anti-HIV drug discovery, but these fungi can also provide very potent inhibitors that can possibly out-perform drugs in use today.

From a mechanistic standpoint, these studies have shown that the isolated compounds do not act by inhibiting the viral reverse transcriptase enzyme (Table 1). However, the effect of the inhibitory compounds on HIV-1 entry and protease enzyme function remains to be determined. It is possible, nonetheless, that these compounds function to inhibit viral replication through a novel mechanism, as they were isolated from a novel source. Regardless of the mechanism, these compounds are not toxic to cells at effective concentrations that inhibit the virus, which would suggest that there is more of an effect on viral proteins than cellular ones. A thorough characterization is underway to fully understand these compounds and how they function to inhibit HIV-1 replication.

\section{CONCLUSION}

A majority of the currently available anti-retroviral drugs targets the viral enzymes protease and reverse transcriptase. While these drugs are effective at reducing viral replication, they result in many unpleasant side effects and the eventual emergence of drug-resistant viral strains is a problem [5]. This highlights the need for development of new anti-HIV drugs, if the HIV-1 epidemic is to be successfully contained. Our studies evaluating endophytic fungal extracts resulted in promising new possibilities for the discovery of novel antiHIV-1 drugs by isolating four compounds that inhibit viral replication. In addition, as these inhibitors originated from a previously unexplored resource, the mechanism of action for these new compounds may also prove to be novel. Taken together, these studies could provide new weapons to fight the war on HIV-1 and AIDS.

\section{METHODS}

\section{Production of Crude Extracts from Endophytic Fungi}

Several hundred endophytic fungal strains from desert plants were grown on either solid or liquid media cultures. Solid media cultures of fungal strains were processed by adding methanol to each growth flask, followed by sonication in an ultrasonic bath to kill the organism, and filtration through Celite-545. The filtrate was concentrated under vacuum to half in volume, extracted with ethyl acetate, dried over anhydrous sodium sulfate and evaporated to obtain the crude extracts. Liquid media cultures were extracted with ethyl acetate, dried, and evaporated under vacuum to yield crude extracts. We first determined the cytotoxicity of these abstracts and found that 100 fungal extracts showed less than $30 \%$ cytotoxicity. These non-toxic fungal extracts were evaluated for their ability to inhibit HIV-1 replication in T-lymphocytes. The endophytic fungal species which produced extracts that showed maximum inhibition of HIV-1 replication were identified; extract B was derived from a Phoma-like fungal strain inhabiting the root tissue of an unidentified Ephedra species, extract $\mathrm{G}$ was derived from the endophytic fungal species Alternaria tenuissima inhabiting the stem of the Sonoran desert plant Quercus emoryi, extract I was derived from an Aspergillus species inhabiting the stem tissue of Caesalpinia gilliesii.

\section{Fractionation of Endophytic Fungal Extracts}

Crude extracts that were not cytotoxic but inhibited HIV1 replication were fractionated several times to isolate the individual compounds present within each extract. In order to generate enough crude extracts to proceed with fractionation, previous cultures that yielded active crude extracts were grown on a large scale and the crude extracts were again isolated, with large scale extracts $\mathrm{CZ}$ and DA originating from large scale culture of the culture that yielded B, large scale extract DB originating from large scale culture of the culture that yielded G, and large scale extract DC originating from large scale culture of the culture that yielded I. Fractionation was performed using a combination of solvent-solvent partitioning and Sephadex LH-20 Gel permeation chromatography on large scale liquid media cultures [21]. Briefly, liquid cultures (10 L) were filtered through Whatman No. 1 filter paper. The yellow filtrate (10 L) was extracted with ethyl acetate (EtOAc) $(4 \times 2 \mathrm{~L})$ and evaporated under reduced pressure to afford a dark yellow residue $(530 \mathrm{mg})$. Second batch liquid culture $(10 \mathrm{~L})$ under similar conditions gave another EtOAc extract $(870 \mathrm{mg})$. The EtOAc extracts were combined (1.4 g) (DB) and partitioned between hexane and $80 \%$ aqueous methanol $(\mathrm{MeOH})$. The $80 \%$ aqueous $\mathrm{MeOH}$ fraction was diluted to $50 \%$ by the addition of $\mathrm{H}_{2} \mathrm{O}$ and extracted with $\mathrm{CHCl}_{3}$. Evaporation of the $\mathrm{CHCl}_{3}$ fraction under reduced pressure yielded dark residue (DB-2) $(595.3 \mathrm{mg})$. A portion $(550 \mathrm{mg})$ of DB-2 was subjected to gel permeation chromatography on a column of Sephadex LH-20 (20 g) in hexane- $\mathrm{CH}_{2} \mathrm{Cl}_{2}(1: 4)$ and eluted with $300 \mathrm{~mL}$ each of hexane- $\mathrm{CH}_{2} \mathrm{Cl}_{2}$ (1:4), $\mathrm{CH}_{2} \mathrm{Cl}_{2}$-acetone (3:2), $\quad \mathrm{CH}_{2} \mathrm{Cl}_{2}$-acetone (1:4), $\quad \mathrm{CH}_{2} \mathrm{Cl}_{2}-$ $\mathrm{MeOH}$ (1:4), and $\mathrm{MeOH}$. Six fractions were collected, including the active fractions: DD $(72.2 \mathrm{mg})$, DE $(56.8 \mathrm{mg})$, 
DF (102.5 mg), and DG (114.8 $\mathrm{mg})$. Column chromatography of fraction DD (72.2 $\mathrm{mg}$ ) on lichroprep diol Si gel (4 g) by elution with $\mathrm{CH}_{2} \mathrm{Cl}_{2}$ followed by preparative TLC on normal phase silica gel (IPA- $\mathrm{CH}_{2} \mathrm{Cl}_{2}, 3: 97$ ) afforded compound DK $(1.9 \mathrm{mg})$. Purification of fraction DE $(56.8$ $\mathrm{mg}$ ) by column chromatography on normal phase Si gel by elution with increasing amounts of acetone in $\mathrm{CH}_{2} \mathrm{Cl}_{2}$ afforded compound DL (15.0 mg). Column chromatography of fraction DF $(102.5 \mathrm{mg})$ on normal phase Si gel $(4.0 \mathrm{~g})$ by elution with increasing amounts of acetone in $\mathrm{CH}_{2} \mathrm{Cl}_{2}$ followed by preparative TLC on normal phase Si gel (IPA$\left.\mathrm{CH}_{2} \mathrm{Cl}_{2}, 3: 97\right)$ afforded compound DM, (3.1 mg), DN (3.7 $\mathrm{mg})$, DP $(11.2 \mathrm{mg})$. The purity of all isolated compounds was shown to be over $95 \%$ by chromatographic and spectroscopic analysis. The techniques used included thinlayer chromatography (TLC), and ultra-violet (UV), infrared (IR), nuclear magnetic resonance (NMR), and mass spectroscopy (MS). Identification of all known compounds involved comparison of their spectroscopic data (NMR and MS) with those reported.

\section{Culture of Cell Lines}

All cell lines and viruses used in this study were obtained from the National Institutes of Health AIDS Research and Reference Reagent Program. A3.01 cells, a T4-lymphocyte cell line known to support HIV-1 infection, were cultured in RPMI 1640 supplemented with $10 \%$ fetal bovine serum (FBS), $50 \mathrm{U} / \mathrm{mL}$ penicillin and $50 \mu \mathrm{g} / \mathrm{mL}$ streptomycin (Invitrogen). Cells were fed every three days with fresh media.

\section{Evaluation of Cytotoxicity of Antiviral Extracts, Fractions, and Compounds}

MTT assays were used to determine the cytotoxicity of the crude extracts, fractions, and compounds used in this study. Briefly, the tetrazolium salt MTT [3-(4,5Dimethylthiazol-2-yl)-2,5-diphenyltetrazolium-bromide] is metabolized by mitochondrial succinic dehydrogenase activity of proliferating cells to yield a formazan reaction product. To evaluate the cytotoxicity of the extract, A3.01 cells were plated in 96-well plates at a concentration of $2 \times 10^{5}$ cells/well. The cells were incubated with the desired concentration of extract, fraction, or compound for a period of 3, 6, and 9 days. On the day of the cytotoxicity assay, MTT (Sigma) was added to each well to a final concentration of $700 \mathrm{ng} / \mu \mathrm{L}$. After at 4 hours at $37^{\circ} \mathrm{C}$, the media was removed and the cells were lysed using DMSO (Sigma), solubilizing the formazan product. The color intensity was estimated in a microtitre plate reader (wavelength of $570 \mathrm{~nm}$ ). For extended cultures, cells were given fresh media and extract, fraction or compound every three days.

\section{Effect of Antiviral Extracts, Fractions, and Compounds on HIV-1 Replication}

A3.01 cells were plated at a density of $5 \times 10^{5}$ cells/well in RPMI containing no serum. Extracts to be tested were added at a final concentration of $2 \mu \mathrm{g} / \mathrm{mL}$ for initial screening. For experiments testing fractionated extracts, the concentrations used were based off of cytotoxicity results. A control using DMSO was included in each experiment at the concentration present in the working solution of the extracts.
Controls with azidothymidine (AZT) (Sigma-Aldrich) at concentrations of $10 \mu \mathrm{M}$ and $20 \mu \mathrm{M}$ were also performed in all experiments. The lab-adapted HIV-1 viral isolate LAV was used in all experiments. For infections, the virus was added at a concentration of 50,000 reverse-transcriptase (RT) counts per well, resulting in a calculated multiplicity of infection (MOI) of approximately 0.005 [26]. The virus was allowed to adsorb for two hours, at which time any unadsorbed virus was removed. The cells were washed with phosphate buffered saline (PBS), and given fresh media containing serum and the extract, fraction, or compound at the desired concentration. Fresh media and extract were given to the cells every three days for 18 days. The culture supernatant that was removed every three days, stored, and the amount of progeny virions present was determined by reverse-transcriptase (RT) assay. Infections were done in duplicate wells per experiment, and each experiment was done in duplicate.

\section{HIV Assay}

The levels of HIV-1 in culture were determined via reverse transcriptase (RT) assay [22]. Briefly, the RT assay consisted of mixing culture supernatant with RT cocktail $(94 \mathrm{mM} \mathrm{KCl}, 5 \mathrm{mM}$ DTT, $63 \mathrm{mg}$ poly-A DNA, $63 \mathrm{mM}$ Tris $\mathrm{pH} 7.8,6 \mathrm{mM} \mathrm{MgCl}_{2}, 6 \mu \mathrm{g}$ oligo-dT DNA, $0.06 \%$ NP-40, $0.1 \%$ Triton-X), which contains ${ }^{32} \mathrm{P}$-dTTP $(800 \mathrm{Ci} / \mathrm{mmol})$. The reaction was incubated at $37^{\circ} \mathrm{C}$ for 2 hours, and then spotted onto DE81 paper (Whatman), which was rinsed in 2x SSC buffer (Invitrogen) to remove unincorporated radioactivity. The amount of ${ }^{32} \mathrm{P}$ present was determined using a scintillation counter (Beckman). The amount of virus present in the culture was then expressed as counts per minute (cpm).

\section{CONFLICT OF INTEREST}

The authors confirm that this article content has no conflict of interest.

\section{ACKNOWLEDGEMENTS}

This work was supported by a grant from the Arizona Biomedical Research Commission (contract \#9014).

\section{REFERENCES}

[1] Ahmad N, Maitra RK, Venkatesan S. Rev-induced modulation of Nef protein underlies temporal regulation of human immunodeficiency virus replication. Proc Natl Acad Sci USA 1989; 86: 6111-5.

[2] Levy JA. HIV pathogenesis: 25 years of progress and persistent challenges. AIDS 2009; 23: 147-60.

[3] Reeves JD, Piefer AJ. Emerging drug targets for antiretroviral therapy. Drugs 2005; 65: 1747-66.

[4] De Clercq E. Antiretroviral drugs. Curr Opin Pharmacol 2010; 10 : 507-15.

[5] Carr A, Cooper DA. Adverse effects of antiretroviral therapy. Lancet 2000; 356: 1423-30.

[6] Gunatilaka AA. Natural products from plant-associated microorganisms: distribution, structural diversity, bioactivity, and implications of their occurrence. J Nat Prod 2006; 69: 509-26.

[7] Newman DJ, Cragg GM, Snader KM. Natural products as sources of new drugs over the period 1981-2002. J Nat Prod 2003; 66: 1022-37.

[8] Shu YZ. Recent natural products based drug development: a pharmaceutical industry perspective. J Nat Prod 1998; 61: 1053-71.

[9] Cragg GM, Newman DJ, Snader KM. Natural products in drug discovery and development. J Nat Prod 1997; 60: 52-60. 
[10] Strobel G, Daisy B, Castillo U, Harper J. Natural products from endophytic microorganisms. J Nat Prod 2004; 67: 257-68.

[11] Carroll GC. Fungal Endophytes in Stems and Leaves: From Latent Pathogen to Mutualistic Smbiont. Ecology 1988; 69: 2-9.

[12] Strobel G, Yang X, Sears J, Kramer R, Sidhu RS, Hess WM. Taxol from Pestalotiopsis microspora, an endophytic fungus of Taxus wallachiana. Microbiology 1996; 142 (Pt 2): 435-40.

[13] Strobel GA, Miller RV, Martinez-Miller C, Condron MM, Teplow DB, Hess WM. Cryptocandin, a potent antimycotic from the endophytic fungus Cryptosporiopsis cf. quercina. Microbiology 1999; 145 (Pt 8): 1919-26.

[14] Polishook JD, Dombrowski AW, Tsou NN, Salituro GM, Curotto JE. Preussomerin D from the Endophyte Hormonema dematioides. Mycologia 1993; 85: 62-4.

[15] Stierle AA, Stierle DB, Bugni T. Sequoiatones A and B: Novel Antitumor Metabolites Isolated from a Redwood Endophyte. J Org Chem 1999; 64: 5479-84.

[16] Bunyapaiboonsri T, Yoiprommarat S, Srikitikulchai P, Srichomthong K, Lumyong S. Oblongolides from the endophytic fungus Phomopsis sp. BCC 9789. J Nat Prod 2010; 73: 55-9.

[17] Phongpaichit S, Nikom J, Rungjindamai N, et al. Biological activities of extracts from endophytic fungi isolated from Garcinia plants. FEMS Immunol Med Microbiol 2007; 51: 517-25.

[18] Guo B, Dai JR, Ng S, et al. Cytonic acids A and B: novel tridepside inhibitors of hCMV protease from the endophytic fungus Cytonaema species. J Nat Prod 2000; 63: 602-4.

[19] Liu L, Liu S, Niu S, Guo L, Chen X, Che Y. Isoprenylated chromone derivatives from the plant endophytic fungus Pestalotiopsis fici. J Nat Prod 2009; 72: 1482-6.
[20] Yu BZ, Zhang GH, Du ZZ, Zheng YT, Xu JC, Luo XD. Phomoeuphorbins A-D, azaphilones from the fungus Phomopsis euphorbiae. Phytochemistry 2008; 69: 2523-6.

[21] Cardellina II JH. Step Gradient Elution in Gel Permeation Chromatography: A New Approach to Natural Products Separations. J Nat Prod 1983; 46: 196-9.

[22] Sundaravaradan V, Saxena SK, Ramakrishnan R, Yedavalli VR, Harris DT, Ahmad N. Differential HIV-1 replication in neonatal and adult blood mononuclear cells is influenced at the level of HIV-1 gene expression. Proc Natl Acad Sci USA 2006; 103: 11701-6.

[23] Nakashima H, Matsui T, Harada S, et al. Inhibition of replication and cytopathic effect of human $\mathrm{T}$ cell lymphotropic virus type III/lymphadenopathy-associated virus by 3'-azido-3'deoxythymidine in vitro. Antimicrob Agents Chemother 1986; 30: 933-7.

[24] Hudson JB, Imperial V, Haugland RP, Diwu Z. Antiviral activities of photoactive perylenequinones. Photochem Photobiol 1997; 65: 352-4.

[25] Diwu Z, Zimmermann J, Meyer T, Lown JW. Design, synthesis and investigation of mechanisms of action of novel protein kinase C inhibitors: perylenequinonoid pigments. Biochem Pharmacol 1994; 47: 373-85.

[26] Sears JF, Repaske R, Khan AS. Improved Mg2+-Based Reverse Transcriptase Assay for Detection of Primate Retrovirus. J Clin Microbiol 1999; 37: 1704-8.

(c) Wellensiek et al.; Licensee Bentham Open.

This is an open access article licensed under the terms of the Creative Commons Attribution Non-Commercial License (http: //creativecommons.org/licenses/by$\mathrm{nc} / 3.0 /$ ) which permits unrestricted, non-commercial use, distribution and reproduction in any medium, provided the work is properly cited. 